\title{
Benefits of the Doubt: Questioning Discipline and the Risks of Queer Reading
}

What does giving the benefit of the doubt cost? And how should we assign value to questions that raise doubts about disciplinary values we've learned to take for granted? Before I delve into queer readings of The Tale of Genji or even frame this book's goals, interventions, and debts to previous scholarship, it felt important to address some concerns, in hopes of smoothing entry into the book proper. This preface reflects on the value of queer approaches to specialists in premodern Japanese literature. In the subsequent introduction, I outline how each chapter's arguments challenge or improve on existing models of understanding in premodern Japanese literary studies and queer studies. I explain, for instance, why I draw on certain strains of queer theory more than others, and I unpack the value of a phenomenological approach across the chapters. Here, however, I contextualize how certain disciplinary locations might condition one's expectations toward $A$ Proximate Remove.

First, an observation: this project has met with more resistance than any other I've undertaken. A Proximate Remove connects Heian literary studies and queer studies in a manner not done before. This is no easy task. And some of the difficulty stems from larger social, historical, and disciplinary structures that configure these fields and influence reactions within them.

I've noticed that the topic of performing queer readings of Genji tends to make many scholars of premodern Japanese literature uneasy. This unease manifests in various ways. Sometimes it crops up in a crossing of arms at the project's mention, 
while other times reservations are expressed about the validity of the projectwithout the commenter having read a page. Some scholars admit the premise sounds interesting, small talking toward inquiring if I myself identify as queer. Informal reservations are mentioned, like, "Try not to overdo it" (Is this an encouragement or a warning?); and, "But Genji only has sex with the boy [Kogimi] once." A host of soft or hard protestations have arisen about the historical validity of the inquiry, such as, "But that's more Edo"; and, "But that's more modern"; or, "But these aren't real people" (as though I don't realize this is a fictional narrative); and, "But these aren't modern people" (as though I don't realize these are characters in an eleventh-century fictional narrative). Written reactions go further, including, "He has no evidence any of these [readings] are what Murasaki Shikibu intended" (as though that was actually the author's real name, or as though the very notion of authorial intention for an eleventh-century tale should be seriously entertained by literary scholars as a guarantor of meaning); and, "The author repeatedly injects sexual innuendo into scenes" (as though Genji needed a shred of help on that score). I mention these examples to do four things: (1) share and think through the nature of the unease they register, with the ideological and disciplinary resistance underpinning it; (2) outline some perceived risks attending my inquiry; (3) anticipate some of the project's potential benefits; and (4) perform solidarity with those who might have encountered similar responses or who seek to bring new energy to their fields.

Rather than discount this pushback as peripheral, theorizing it upfront seems valuable as a critical gesture in itself. This entails not taking negativity for granted but rather, in a queer theoretical spirit, weighing it as a way to consider some of the thematic textual concerns examined in subsequent chapters-such as disorientation, temporal dilation, and disenchantment with normative structures. This might seem like hand-wringing to some, particularly audiences more conversant with queer theory; if you're in that category, please proceed to the introduction proper. However, for readers less versed in that style of inquiry, and perhaps more skeptical toward it, this section attempts to lay out the analytical terrain at a meta level.

A Proximate Remove will in some ways be a challenging book. This is because of the book's arguments and engagement with a varied conceptual archive unfamiliar to many scholars in the field of premodern Japanese studies, on the one hand, and a historiography alien to queer studies scholars, on the other. My goal is not to incite a love-hate relationship but rather to expand the horizon of interpretive possibilities currently available in premodern Japanese literary studies. Without belaboring the point, I should merely say up front that a lack of a sustained engagement with queer theory within the field is precisely what my manuscript seeks to address.

Part of what makes the book challenging is that it questions fundamental and often unmarked beliefs about the nature of desire and disciplinary orientations 
toward reading and writing themselves. Consequently, it seemed prudent in this preface to identify certain disciplinary habits and expectations and indicate potential instances of friction. So from the outset we should ask, How does posing queer questions accentuate, reinforce, or erode disciplinary norms-within premodern Japanese literary studies primarily? And how should we understand the risks and benefits of that doubt?

Although queer studies grew out of antidiscriminatory activism centered on sexual identity, and some critiques still hew close to that legacy, the field has expanded beyond those concerns since its early 1990 inception in the United States. Some recent approaches in queer studies recognize facets of everyday experience that speak to possibilities overshadowed by normalizing regimes, with compulsory heterosexuality being just one draconian example; others reconsider antinormativity's dominant role in queer theorization or pursue posthuman critiques inclined to minimize human sexuality's privileged position through a broader focus on animacy. ${ }^{1}$ On this point, I am careful to never capitalize queer theory so as to not reify it as some monolithic entity or flatten its conceptual diversity.

Often, the analytical object of queer theory is not queerness, which is associated vernacularly with nonnormative or LGBTQ+ identities, but rather complex processes that structure exclusion or reproduce repressive styles of sociality. Thus, one way to understand queer studies is as a practice of asking questions more openly-be it in love, law, or literature-without taking prohibitive assertions at face value. Insofar as queer theory ideally pursues better, less constrained circumstances for living, it works to diagnose or critically intuit stimuli, gestures, turns of phrases, and irruptions large and small that disclose chinks in the armor of dominant logics or signal ways to imagine otherwise.

By positing such an array of phenomena as deserving analysis, some scholars protest that queer theory becomes a "theory of everything." This complaint can precede a dismissal indicative of deeper-seated issues. My hunch is that this qualm stems more from unspoken homophobia, which lets a closeted prejudice masquerade as dispassionate appraisal. I wouldn't claim this sort of homophobia constitutes full-blown bigotry; rather, it persists as a constitutive element of heteronormative society. Against such judgments, I would counter that queer theory is no more a theory of everything than theories examining class, gender, or race. On the one hand, Black feminists like Kimberlé Crenshaw have made clear that these powerfully structuring social categories must be considered in their intersectional relation to one another. ${ }^{2}$ On the other hand, intersectionality in a Black feminist context or queer-of-color critique has yet to secure cachet within Japanese studies. Although younger than Marxist or psychoanalytic criticism, queer theory both overlaps and exceeds some of those more established lenses' concern about economies, inequalities, and subjectivities.

This book practices a form of queer reading composed of several interpretive approaches. Importantly, as used here, the term queer does not index erotic 
exchange or identity politics. Generally speaking, queer approaches question the dominant, normative logics governing the embodied experience of space, time, and feeling. Within literary analysis, queer approaches pause over irruptions or aporias in a text-fissures of space, time, or feeling - as intervals in which to suspend belief in predominant logics, reorient critical attention, reassess normalized styles of sociality, and rethink habituated patterns of inhabiting the world.

In The Tale of Genji's case, these normative logics include the workings of aristocratic patriarchy and imperial succession, and the multifaceted desires undergirding them. To be sure, the eleventh-century narrative depicts the entwinement of heterosexual reproduction with political fortune that conditioned aristocratic consciousness of the time. Yet the text continually dramatizes desire's propensity to veer off track and features a range of "nonproductive" relations that literary scholars like Kimura Saeko stress as central to Heian narratives. ${ }^{3}$ Accordingly, queer textual approaches involve apprehending conspicuous and subtle encounters with uncertainty and disorientation, without necessarily centering on sexuality and antinormative subversion. My goal is to locate moments askew of the text's prevailing vectors of authority, temporality, and social intercourse. I therefore emphasize the visual, aural, tactile, and spatial attributes of scenes to provide a sensorial account that accentuates embodied experiences of contingency: encounters where institutional, physical, or psychic stability falters. My own use of queer as a figure of indeterminacy is strategic, and my readings of Genji demonstrate the irreducibility of queerness to matters linked exclusively or even primarily to sexuality, as queer entails a far broader array of affections, orientations, and social relations.

That said, raising the issue of sexuality can prove valuable-pedagogically and conceptually. For instance, as I delineate in chapter 1, where I explain the notion of false flags and problematize the matter of misreading suggestions of sexual contact, my decision to sometimes concentrate on scenes surrounding erotic desire is not simply a matter of injecting innuendo for kicks. Rather, this tendency reflects a deliberate choice to raise such possibilities precisely to demonstrate their limitations. A more limited reading strategy would trawl the text for "gay" desireideally hidden - to expose and diagnose. In short, I perform readings that play up this capacity for misreading to undercut them and accentuate potentials irreducible to sexuality-despite its potent resonance throughout the narrative. To queer The Tale of Genji is not simply to magnify its scenes of homosocial camaraderie or amplify homoerotic murmurs but rather to take cues from the text's own intense circumspection toward all normative social formations: a productive unease from which past and present readers might draw lessons.

Hence both the Heian text and the discipline currently enclosing it seem enriched by a turn to queer reading. A Proximate Remove's larger critical project-echoing Genji's own-is to practice a mode of reading wary of absolutist pronouncements regarding desire, politics, textuality, or method. Indeed, one benefit of that queer theoretical emphasis is its instructive skepticism toward aspirations for empiricist 
certitude or epistemological closure. But how might we pursue such a project, especially given the fascinating skepticism queer reading itself arouses among premodernists in Japanese studies in particular?

In raising the question of queer approaches to Heian literature, I'm reminded of something Norma Field wrote about The Tale of Genji more than thirty years ago. Extrapolating from her feminist approach, we get a better idea of what reading Genji might teach us about how to read queer theory-as a mode of attention deserving the benefit of the doubt. Field argues for "novelistic" reading in an enlightening manner:

A novel is lost if its reader refuses to think novelistically. This means in part that at a certain point every reader-and this point will be different for each reader and each reading - must gain some distance from inherited points of view (principles of theory, tools of the trade such as information on historical allusion, rules of etiquette, fashions in incense concoction) simply to make room for other perceptions. ... In fact, a great deal of my book is an appeal to other readers of the Genji to notice, for example, a form of address, or the presence of a certain musical instrument. ${ }^{4}$

Like Field, I am also "continually struck by minute points of resonance, by extraordinarily complicated and unfamiliar configurations," that Genji presents, and my response to these textual irruptions is to read them through a queer frame. Field's suggestion that open, attentive readers "gain some distance from inherited points of view . . . to make room for other perceptions" anticipates a basic premise of A Proximate Remove. This recommendation to "gain some distance" applies to the "principles of theory" and "tools of the trade" germane to both more and less theoretical approaches. Made in 1987, before theorizing the everyday became customary in queer studies, Field's parenthetical admonition to "never underestimate the potency of the banal" recuperates the banal as a resource for theorizing-even when the textual object or cultural practices are far removed from that familiar everyday:

Take, for example, the pervasive aestheticism of the Heian period [794-1185]. Much has been made of the refinement of Heian sensibilities-the excruciating devotion to details of color, scent, hand, or season. ... For now I would like to caution the reader to be attentive to these aesthetic matters as languages that are deployed throughout the tale. Certainly, from our own point of view, some of these interests seem precious at best and perniciously frivolous at worst. ${ }^{5}$

These details stir attention for both the intricacy of their respective grammars and for the way they might estrange or obstruct present-day perspectives. Importantly, Field here supplements the question of aesthetic interpretation by anticipating the negative feelings that accompany it. Shades of disgust seep from the chasm between "our point of view," or recourse to accustomed disciplinary regimens, and Heian courtiers' "excruciating devotion" to sensibilities that can frustrate our interpretive encounter. I stress this last sentence about how our disciplinary norms 
discredit certain alienating forms of critical interest because it recalls the dubious, defensive, or dismissive tinges that have colored several responses I've gotten in proposing queer readings of Genji. Such responses-be they principled, cynical, well-informed, or otherwise-signify symptoms of a devotion to insular disciplinary norms according to which queer does not translate smoothly. As a remedy to this misapprehension, Field recommends that "we learn to follow the other languages-of dress, of calligraphy, of floral and musical preference, of incense concoction. This implies, of course, expenditure of effort to learn about these matters. We must be cautious, however, so as not to force the novel to conform to such expertise as we have gained but rather to use it to help us apprehend that incense concoction, for instance, is one language among others within the novel." ${ }^{\prime}$

Fluency in all these languages is impossible in a non-Heian world, thus Field concedes that effort spent learning to follow the other languages is enough. What matters here is the recognition of potential value added: the lending of a benefit of the doubt to subsidize the effort needed to fathom less familiar idioms. Alongside calligraphy or incense concoction, why not position queer theory as another language worth learning to follow, an idiom whose capacity to enhance our sense of these other Heian idioms has yet to be explored sufficiently?

Viewed another way, queer theory signifies a style of paying attention to these multiple languages already present in Genji. In this sense, far from being an imposition of the foreign, a recourse to queer theory represents a means of engaging those native idioms anew in hopes of discerning different, formerly subdued scents and frequencies. In other words, queer theory should not be seen as a wholesale displacement of more familiar styles of analysis but instead be embraced for its refinement and extension of them. Field's point extends beyond Genji. It applies to thinking about the type of work that literary scholars in general can pursue in terms of being open to aesthetic grammars circulating alongside written languages. ${ }^{7}$

Some will counter that the crucial difference between these idioms is that where calligraphy or incense belong to Genji's world, queer theory does not. Fair enough. Yet none of these aesthetic/political languages is sovereign, regardless of its provenance. Even Genji’s "native" languages (e.g., incense blending, calligraphy, painting, kickball) are partial; each of them at some level supplements another, calling to be read beside its counterparts. Moreover, a millennium's gap estranges these idioms from any post-Heian critic. Fantasies of absolute accuracy or access aside, interpreting them might thus require all the help we can get. Therefore, let's pose the question this way: What might queer theory teach us about Heian calligraphy and incense that prevailing historiographies or patterns of expertise cannot?

Such questions can feel promising or menacing, depending partly on the disciplines to which one feels most beholden. Alongside personal preference, different disciplinary homes trigger a range of inclinations toward or against a mode of questioning I describe as queer. Sketching some of these inclinations helps us 
recognize how queer's potential as an interpretive tool is managed among different audiences that are more (or less) inclined to give it the benefit of the doubt. Indeed, queer theory prompts doubt about the authority of critics who might avoid or embrace it and raises productive, if possibly unsettling, questions about the ideological and pedagogical stakes of reading within and beyond our disciplinary comfort zones.

Queer resonates as a magnetic term; it attracts and repels across a range of intellectual orientations. Queer shines as more attractive (or sexier) for certain editors who have a sense of the term's contemporary market value within the beleaguered realm of academic publishing. Meanwhile, some scholars resent the term on the basis of this very same perceived appeal, therefore dismissing this project out of hand as merely trendy or expedient. This has happened more among premodern Asianists than in other company, and generally with more established scholars; it has been less of an issue with female, queer, or junior scholars.

Some suspicion stems from a concern about the applicability of queer theory to medieval Asian texts. Sometimes, this is a concern about subsuming a particular old Asian example beneath the hegemonic banner of a Western paradigm sprouting from the United States in the 1990s. This concern can stem from legitimate apprehensions about legacies that subordinate Asia as a passive object ripe for analysis through non-Asian methods. Folks bearing this mindset don't want the Asian object to be overtaken by the (implicitly American) queer. Granted, a conscientious desire for reciprocity or parity seems reasonable enough-admirable, even. However, sometimes it's a ruse-a way to register discomfort about other, less formalized or more embarrassing worries through righteous posturing.

The amount of concern-or defensiveness-hinges on how much of a burden or incursion queer represents. A recent roundtable among Japanese scholars on queer reading mentions various factors hampering queer studies' impact on modern Japanese literary studies in Japan. These range from celebrated feminist scholar Ueno Chizuko's indictment of "a theory phobia among Japanese literature scholars" (nihon bungaku kenkyūsha ni okeru riron fobia) to the link between sexual identity and queer studies. ${ }^{8}$ This perception, that doing queer work requires a particular identity, breeds a reluctance in literary studies that doesn't exist in fields like sociology, where queer studies in Japan is most advanced. ${ }^{9}$

Meanwhile, for some scholars in Japan and elsewhere, queer theory epitomizes an outer limit. Where thematic, new historicist, or feminist criticism seems permissible enough, queer critique makes some folks more uneasy with the aura of excess it emits. It can code as too vanguard, too antiestablishment, too flimsy, too neoliberal, too consumerist, too foreign, too irreverent, too sexual, too smug, too permissive or promiscuous in its methods and choice of analytical objects, too slippery or soft to reckon suitably with hard textual or historical evidence. These perceptions coat disciplinary boundaries and assumptions that tend to go unmentioned. But then this privileged silence is what makes them such sturdy norms. 
I've had scholars proceed to explain why this queer stuff was ill-suited or just wouldn't work with Genji without engaging queer studies texts I referenced or acknowledging their ignorance of the issues. Mansplaining of this sort revolved around notions of scholarly rigor without the acknowledgment of even rudimentary literacy in queer studies as a component of due diligence. Such an implicit or explicit devaluation of a queer theoretical approach speaks to disciplinary norms-regarding legibility, empiricism, and proper object choices, for instancethat surface in comportments where shades of unease, bemusement, condescension, and low-key paranoia try to coalesce into the guise of sound advice.

Not that this style of negativity stays anchored to a single disciplinary home or demographic. For, as Lauren Berlant and Michael Warner explain, "even inside the academy, questions about queer theory's political utility are occasionally not in the best faith. Sometimes they serve to ward off theory from a model of gay studies that has a more affirmative relation to its imagined constituency. In this context, queer commentary provides exactly what some fear it will: perspectives and archives to challenge the comforts of privilege and unself-consciousness."10 This challenge goes both ways. It applies as much to queer theorists as to premodern East Asianists, each with their respective comforts, expertises, biases, pretensions, and claims to authority. To be sure, queer studies has been quite limited in scope, with ancient Greece and early modern Europe getting the most attention after modern Western societies. This habit no doubt contributes to the worry that queer theory might not work with premodern Asian material.

Some folks are more sympathetic, though, and a robust benefit of the doubt offsets their skepticism. For these scholars of premodern Asia, queer theory might still feel suspect, but is not dismissed outright as unviable, partially because it seems consonant with feminist critiques that have burgeoned since the mid-1980s. For instance, among scholars in the Japanese academy aligned with or influenced by the Narrative Research Association (monogatari kenkyūkai), a turn toward queer theory reads as a natural outgrowth of explorations of textuality, sexuality, and phenomenology already undertaken for decades by figures like Mitani Kuniaki, Kawazoe Fusae, Mitamura Masako, and Matsui Kenji, whose contributions I outline in the introduction. Conversations with scholars of this sort have a different quality than ones with the mansplainers. There's genuine curiosity, less posturing, less visible tension. Talk turns to which textual depictions might deserve most scrutiny and why. Queer signifies less as threat than as opportunity in this case, and any pushback feels more measured and constructive, not reactionary.

My experience suggests that queer theory perturbs to a degree that tropes like status, gender, performance, space, and agency don't currently. A main difference is that unlike queer, those terms function more as interchangeable, relatively benign thematic lenses than as comprehensive challenges per se. These other lenses can feel more comfortable or applicable, partly because they don't carry the same ambient stigma born of homophobic culture and partly because they don't spotlight the 
critic's sexual identity to a comparable extent. This makes me think that this book's topic taps a reservoir of feelings that well up in unexpected ways. Reactions I've received have made it feel like invoking the term queer highlights larger presumptions and expectations-within and beyond disciplinary boundaries.

Berlant and Warner's "What Does Queer Theory Teach Us about X?” (1995) helps explain the sensitivities that surface when queer scrapes such normative structures. They write, "The critical mass of queer theory is more a matter of perception than of volume. Queer is hot. . . . The association with the star system and with graduate students makes this work the object of envy, resentment, and suspicion. As often happens, what makes some people queasy others call sexy."11

Queer theory, in other words, attracts bad affective energy because of its perceived popularity-or some sort of imperative to be more contemporary, politically correct, and caring toward minorities?-regardless of its potential interpretive efficacy. But if this negativity arrives from outside queer studies, a friction also exists within queer studies, one stemming from the same ubiquitous reach its detractors condemn with the "theory of everything" rhetoric. Thus, as Berlant and Warner observe, the value of queer commentary also wavers among commentators committed to it: "The panicky defensiveness that many queer and non-queer-identified humanists express has to do with the multiple localities of queer theory and practice. Separately, these localities often seem parochial, or simply local-like little ornaments appliquéd over real politics or real intellectual work. They carry the odor of the luxuriant." ${ }^{12}$

In either context, queer transmits an excess that solicits resistance at varying degrees, from multiple sectors of the academy. We could downplay this claim by highlighting the time that's passed since Berlant and Warner's essay was published, assuming that bad feelings have mellowed with age. But that would overlook structural realities of the contemporary academy. Feelings have no doubt changed, but where and how much? The academy's topography is far from uniform. Specifically, asymmetrical disciplinary and institutional histories (relations to Cold War paradigms, activist movements, and marginalized communities) and prevailing attitudes (regarding the value of linguistic training, translation, theory, and popular/elite or modern/premodern objects) influence the differential rate at which queer theory earns currency within disciplines. Generally speaking, this cachet is higher in English, comparative literature, anthropology, gender studies, ethnic studies, performance studies, American studies, and Asian American studies than in history and East Asian studies, for example. And these disciplinary fissures get more jagged once we introduce historical period as a variable to differentiate further within fields of inquiry in Japanese studies: modern overshadows premodern and contemporary, and a project attempting to bring a premodern text and contemporary theory into conversation arguably suffers double.

Recognizing the structural unevenness of this valuation and the fluctuating structures of feeling that attend it, it becomes important to question the 
possibility-and desirability_of queer reading within environments prone to judge it as alien. Although "humanists" has a wide berth, Berlant and Warner (who were both tenured Americanists in English departments when they wrote the essay) might take for granted queer's appraisal in less tolerant atmospheres. After all, a "luxuriant" odor cushions queer with the benefit of the doubt, but in other institutional "localities," it might just reek. Some of the judgments I've heard regarding queer theory disparage it as arbitrary. But the same applies for any number of routines in our fields-like European language requirements, say-that somehow feel more fragrant, cosmopolitan, serious, or valuable.

Which languages or idioms become naturalized as valuable or useful frames these recent scenes when I have shared my work on Genji. Returning to Field's insights about reading Genji, queer theory currently represents a language whose use value within the realm of Japanese literary studies remains relatively unacknowledged and untested. This predicament is not unlike that once faced by poststructuralism, postcolonial theory, or gender theory, critical idioms that now seem far less foreign and superfluous than they did in the not-so-distant past. I hope that the ensuing readings encourage others to engage this idiom to read beyond current conventions and rethink how we engage literature in our research, teaching, and broader lives.

There's a lesson here, one worth bearing in mind as this book gets underway. A caution toward our own expertise-be it empirical or conceptual, concrete or abstract-helps temper the mandate to domesticate or disregard those queer questions and impulses, the "minute points of resonance" and "unfamiliar configurations" that unsettle our prevailing professional sensibilities. The early '9os advent of queer commentary may have grated because of the "wrenching sense of recontextualization it gave." ${ }^{13}$ But thirty years on, it needn't any longer. If it vexes us, we should at least be able to mark that feeling, take it seriously, historicize it, and attempt to theorize openly the overlapping norms and contexts that sparked it. We should, in other words, learn how to give that doubt the benefit of an attentive queer reading. 